\title{
Identification and expression pattern analysis of the glucosinolate biosynthetic gene BoCYP83B1 from broccoli
}

\author{
R. XU, W. W. KONG, Y. F. PENG, K. X. ZHANG, R. LI, and J. LI* \\ College of Life Sciences, Northeast Agricultural University, Harbin, 150030, P.R. China
}

\begin{abstract}
Glucosinolates are a branch of amino acid-derived metabolites, which are specifically found in Brassicales. In Arabidopsis, tryptophan derived indolic glucosinolates are required for plant defense against a wide range of pathogens and herbivores due to their strong antimicrobial activity and potential signaling function. An important enzyme in indolic glucosinolate biosynthesis pathway is CYP83B1, which oxidizes indole-3-acetaldoxime, a precursor of indole-3-acetic acid (IAA). In this study, we reported isolation and expression characterization of a CYP83B1 gene from Brassica oleracea L. var. italica Plenck, which we termed BoCYP83B1. Overexpression of BoCYP83B1 in Arabidopsis resulted in an altered glucosinolate profile and early flowering phenotype. By expressing the reporter gene $\beta$-glucuronidase under the control of the BoCYP83B1 promoter in Arabidopsis, we analyzed the spatial expression pattern of BoCYP83B1 under normal growth conditions as well as in response to several hormones and stresses. The BoCYP83B1 was primarily expressed in vascular tissue through the almost whole plant. It was strongly induced by methyl jasmonate, 1-amino-1-cyclopropanecarboxylic acid, salicylic acid (SA), gibberellin, and IAA, suggesting its involvement in complex signaling pathways. Mannitol, $\mathrm{NaCl}, \mathrm{UV}$, and Flagelin 22 significantly up-regulated $B o C Y P 83 B 1$ expression, indicating its possible role in stress response. Interestingly, the response of $B o C Y P 83 B 1$ to $\mathrm{SA}$ and $\mathrm{NaCl}$ showed tissue specificity. Thus, BoCYP83B1 might have different functions in different tissues.
\end{abstract}

Additional key words: ethylene, gibberellins, indole-3-acetic acid, jasmonates, mannitol, salinity, UV radiation.

\section{Introduction}

Glucosinolates are a class of amino acid-derived specialized metabolites, which are especially found in the Brassicaceae family (Agerbirk and Olsen 2012). This family includes many economically important vegetables and the model plant Arabidopsis thaliana. According to their various precursor amino acids, glucosinolates are broadly divided into aliphatic glucosinolates (derived from Leu, Ala, Val, Ile, or Met), indolic glucosinolates (derived from Trp), and aromatic glucosinolates (derived from Phe and Tyr) (Halkier and Du 1997, Halkier and Gershenzon 2006). Once hydrolyzed by thioglucosidase, e.g., myrosinase, glucosinolates release a range of hydrolysis products with diverse biological activities (Halkier and Gershenzon 2006, Textor and Gershenzon
2009). In plants, glucosinolates and their products are essential for an effective defense response to a wide range of pathogens and herbivores(Zhang et al. 2006, Clay et al. 2009, Andersson et al. 2015, Frerigmann et al. 2016, Halkier 2016). These metabolites have also high pharmaceutical values (Fahey et al. 1997, Rose et al. 2000, Fahey et al. 2002).

In addition to plant defense and human health protection, biosynthesis of indolic glucosinolates is related to other metabolic pathways (Bak and Feyereisen 2001, Bak et al. 2001, Nafisi et al. 2007). During biosynthesis of indolic glucosinolates, $\operatorname{Trp}$ is firstly converted to indole-3-acetaldoxime (IAOx) by CYP79B2/B3; then, IAOx is converted to indole-3-acetonitrile oxide in a

Submitted 15 November 2017, last revision 24 January 2018, accepted 26 January 2018.

Abbreviation: ABA - abscisic acid; ACC - 1-amino-1-cyclopropanecarboxylic acid; CaMV 35S - cauliflower mosaic virus promoter; CDS - coding sequence; Flg22 - Flagelin 22; GA - gibberellic acid; GUS - $\beta$-glucuronidase; IAA - indole-3-acetic acid; IAOx indole-3-acetaldoxime; MeJA - methyl jasmonate; MS - Murashige and Skoog; NCBI - National Center for Biotechnology Information; RACE - rapid amplification of cDNA ends; RT-PCR - reverse transcription PCR; SA - salicylic acid; UTR - untranslated region.

Acknowledgments: This work was supported by the National Natural Science Foundation of China (NSFC No. 31570298), Science Foundation of Heilongjiang Province (No. C2017031), and Science and Technology Research Project of Education Department of Heilongjiang Province (No. 12531003).

* Corresponding author; e-mail: lijing@neau.edu.cn 
reaction catalyzed by CYP83B1 (Hull et al. 2000, Mikkelsen et al. 2000, Hansen et al. 2001). A series of enzymes including $\gamma$-glutamyl peptidase 1 (GGP1), superroot 1 (SUR1), UDP-glucosyl transferase 74B1 (UGT74B1), and sulfotransferase 16 (SOT16) are involved in the subsequent pathway leading to the core structure, indol-3-ylmethyl glucosinolate (Grubb et al. 2004, Mikkelsen et al. 2004, Piotrowski et al. 2004, Geu-Flores et al. 2009). The IAOx is an intermediate in the biosynthesis of indolic glucosinolates and a precursor for indole-3-acetic acid (IAA) and a phytoalexin camalexin (Nafisi et al. 2007, Moldrup et al. 2013). The Arabidopsis recessive surl and cyp 83 bl mutants show a high-auxin phenotype, which is thought to arise due to blockage of the IAOx-glucosinolate pathway, resulting in accumulation of IAOx, which is channeled into IAA (Delarue et al. 1998, Barlier et al. 2000, Bak and Feyereisen 2001, Bak et al. 2001, Naur et al. 2003, Nafisi et al. 2006). Thus, IAOx constitutes a key branching point between primary and secondary metabolism. As the enzyme catalyzing the conversion of IAOx, CYP83B1 plays an important role in balancing IAOx and must be tightly regulated to maintain IAA homeostasis and control its flow into different parts.

The glucosinolate metabolic pathway and the IAOx have been well studied in the model plant Arabidopsis

\section{Materials and methods}

Plants, growth conditions, and treatments: Seeds of broccoli (Brassica oleracea L. var. italica Plenck) cv. Qingxiu were placed on moist filter paper in Petri dishes under continuous irradiance for $3-4 \mathrm{~d}$. The germinated seedlings were transplanted to soil and grown in a greenhouse under a 16-h photoperiod, a photosynthetic photon flux density of $100 \mu \mathrm{mol} \mathrm{m} \mathrm{m}^{-2} \mathrm{~s}^{-1}$, a temperature of $23{ }^{\circ} \mathrm{C}$, and a relative humidity of $70 \%$ for 4 weeks. Arabidopsis thaliana L. ecotype Columbia (Col-0) wild type and transgenic plants were grown under the same conditions.

To investigate the expression pattern of $B o C Y P 83 B 1$,

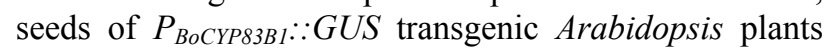
were allowed to germinate on a $1 / 2$ Murashige and Skoog (MS) agar medium for $5 \mathrm{~d}$. Then, the seedlings were transferred to new 1/2 MS agar media containing $25 \mu \mathrm{M}$ methyl jasmonate (MeJA), $200 \mu \mathrm{M}$ salicylic acid (SA), $10 \mu \mathrm{M}$ abscisic acid (ABA), $20 \mu \mathrm{M}$ 1-amino-1-cyclopropanecarboxylic acid (ACC, precursor of ethylene), $10 \mu \mathrm{M}$ gibberellic acid (GA), $5 \mu \mathrm{M}$ indole-3-acetic acid (IAA), $1 \mu \mathrm{M}$ Flagelin (Flg) 22, $200 \mathrm{mM}$ mannitol, or $150 \mathrm{mM} \mathrm{NaCl}$. Then, the seedlings were grown for 1, 2, 3, and $4 \mathrm{~d}$. For treatments by UV radiation, high temperature, and low temperature, the seedlings were exposed to UV (254 nm) for $1.5 \mathrm{~h}, 40{ }^{\circ} \mathrm{C}$ for $2 \mathrm{~h}$, or $4{ }^{\circ} \mathrm{C}$ for $2 \mathrm{~h}$. Wounding treatment was performed by cutting cotyledons in half prior to $\beta$-glucuronidase (GUS) detection.
(Barlier et al. 2000, Bak and Feyereisen 2001, Bak et al. 2001, Hansen et al. 2001, Naur et al. 2003, Morant et al. 2010). However, in other glucosinolate-containing crops, the metabolism of IAOx and the characteristics of the gene encoding IAOx-metabolizing enzyme remain unclear.

Broccoli is a worldwide important vegetable and contains abundant glucosinolates. The biotic stress resistance and medical value of broccoli is largely dependent on glucosinolate production (Fahey et al. 1997, Latte et al. 2011, Ares et al. 2013).

In this article, we report the isolation and identification of a CYP83B1 in broccoli named BoCYP83B1. Overexpression of $B o C Y P 83 B 1$ in Arabidopsis resulted in an early flowering phenotype and affected the glucosinolate profile. This phenotype resembles the Arabidopsis overexpressing AtCYP83B1, which suggested the function of BoCYP83B1 is similar to its ortholog in Arabidopsis. Though the expression of BoCYP83B1 partially overlapped with the one of Arabidopsis, it displayed a distinct pattern both in spatial distribution and in response to exogenous hormones and stress treatments. The aim of our study was to provide data concerning expression characteristics and the potential functions of BoCYP83B1, which might be helpful for better understanding indolic glucosinolate biosynthesis in Brassica vegetables.

Bioinformatics analysis of BoCYP83B1: Sequences of genes and proteins were obtained from the National Center for Biotechnology Information (NCBI) website (http://www.ncbi.nlm.nih.gov/). Multiple alignments and phylogenetic analysis were performed using the MEGA 5 software. Physicochemical properties were predicted using Protparam (http://web.expasy.org/protparam/), transmembrane prediction was made using TMHMM (http://www.cbs.dtu.dk/services/TMHMM/), hydrophilicity/hydrophobicity were predicted using ProtScale (http://web.expasy.org/protscale/), translational modification of amino acids was predicted using the NetPhos 2.0 server (http://www.cbs.dtu.dk/services/NetPhos/), the secondary structure was predicted and analyzed using SOPMA (https://npsa-prabi.ibcp.fr/cgi-bin/npsa_automat. pl?page $=/ \mathrm{NPSA} / \mathrm{npsa}$ sopma.html), functional domains were predicted by SMART (http://smart.emblheidelberg.de/), and the three-dimensional structure was predicted by Swiss-Model (http://swissmodel.expasy.org/) (Geourjon and Deleage1995, Schultz et al. 1998, Blom et al. 1999, Chen et al. 2003, Gasteiger et al. 2003, Johnson et al. 2008, Biasini et al. 2014).

Generation of the $35 S:: B o C Y P 83 B 1$ construct and transgenic plant: To obtain the full-length mRNA sequence of $B o C Y P 83 B 1$, rapid amplification of cDNA ends (RACE) PCR (Takara, Otsu Shiga, Japan) was 
performed according to the manufacturer's instructions. Two pairs of primers $3^{\prime}$ outer and $3^{\prime}$ inner, $5^{\prime}$ outer ' and $5^{\prime}$ inner (primer sequences are listed in Table 1 Suppl.) were used to obtain the $3^{\prime}$ and $5^{\prime}$ end sequences of the BoCYP83B1 mRNA. Based on the mRNA sequence, the coding sequence (CDS) of BoCYP83B1 was amplified through reverse transcription PCR (RT-PCR). Total RNA was extracted using a TRIzol reagent (Invitrogen, Carlsbad, CA, USA) from four-week-old leaves of broccoli, and the first strand of cDNA was synthesized using a PrimeScript RT reagent kit (Takara). The CDS of BoCYP83B1 was amplified with Ex Taq DNA polymerase (Takara) from the first-strand products using primers BoCYP83B1-F and BoCYP83B1-R (Table 1 Suppl.). The CDS of BoCYP83B1 was cloned into pCAMBIA230035Su expression vector under control of the cauliflower mosaic virus promoter (CaMV 35S) using the USER cloning method described by Nour-Eldin et al. (2006). The recombinant vectors were introduced into the Agrobacterium tumefaciens L. strain LBA4404 and then transformed into Arabidopsis plants using the floral dip method (Clough and Bent 1998). Transgenic seeds $\mathrm{T}_{0}$ were selected on a $1 / 2 \mathrm{MS}$ agar medium containing $50 \mu \mathrm{g} \mathrm{cm}^{-3}$ kanamycin. Three independent $\mathrm{T}_{3}$ homozygous transgenic lines were confirmed and used for the analysis.

Generation of the $P_{\text {BoCYP83B1 }}:: G U S$ construct and transgenic plants: To identify the spatial expression pattern of $B o C Y P 83 B 1$, the $P_{B o C Y P 83 B 1}: \because G U S$ construct was prepared, in which GUS expression was driven by the BoCYP83B1 promoter. A 2kb DNA fragment containing the $B o C Y P 83 B 1$ promoter was PCR-amplified from the genomic DNA with primers BoCYP83B1-pro-F and BoCYP83B1-pro-R (Table 1 Suppl.). The obtained DNA fragment was considered as the promoter of $B o C Y P 83 B 1$, and it was analyzed by PlantCARE (http:// bioinformatics.psb.ugent.be/webtools/plantcare/html/)

(Rombauts et al. 1999). The BoCYP83B1 promoter was cloned into the pCAMBIA3300 GUS expression vector using the USER method (Nour-Eldin et al. 2006). The pCAMBIA3300 GUS was generated from the original pCAMBIA3300 vector by adding the coding sequence of GUS with the USER cloning sites (Nour-Eldin et al. 2006). In the resulting $P_{B \circ C Y P 83 B 1}: \because G U S$ construct, GUS was driven by the $B O C Y P 83 B 1$ promoter.

The construct was transformed into Arabidopsis using the Agrobacterium-mediated floral dip method (Clough and Bent 1998). Selection of transgenic plants was performed by sowing seeds directly on soil followed by spraying the herbicide Basta $(0.2 \mathrm{mM})$ on alternate days starting one week after germination. Three independent

\section{Results and discussion}

Based on the partial CDS of CYP83B1 in broccoli, RACE was performed to amplify the full-length cDNA from the transgenic lines were used in the subsequent analyses.

Analysis of IAA: Extraction, purification, and determination of IAA were performed by an ELISA technique as previously described (Yang et al. 2001). Content of IAA was calculated following Weiler et al. (1981).

Glucosinolate detection: The $35 S: \because B o C Y P 83 B 1$ and wild type plants were grown simultaneously for four weeks. Individual leaves $(50-100 \mathrm{mg})$ and seeds $(20 \mathrm{mg})$ from each plant were harvested. Glucosinolate extraction was performed as described Hansen et al. (2007). High performance liquid chromatography analysis was performed as described by Pang et al. (2009).

Detection of GUS: Histochemical detection of GUS was performed as described Jefferson et al. (1987). Plant material was incubated in a substrate solution containing $2 \mathrm{mM} X$-gluc (5-bromo-4-chloro-3-indoxyl $\beta$-D-glucuronide cyclohexylammonium salt), $50 \mathrm{mM}$ sodium phosphate buffer at $\mathrm{pH} 7.0,0.5 \mathrm{mM}$ potassium ferricyanide, $0.5 \mathrm{mM}$ potassium ferrocyanide, $0.1 \%(\mathrm{v} / \mathrm{v})$ Triton $X-100$, and $10 \mathrm{mM}$ EDTA at $37{ }^{\circ} \mathrm{C}$ for $12 \mathrm{~h}$ followed by removal of chlorophyll by submerging the samples in $75 \%(\mathrm{v} / \mathrm{v})$ ethanol. The samples were examined and photographed using a stereomicroscope (Nikon SMZ1270, Tokyo, Japan). Quantitative assay of GUS activity was performed as described by Bhuria et al. (2016).

Real-time PCR analysis: To determine the effects of BoCYP83B1 overexpressing on the glucosinolate metabolism pathway in Arabidopsis, transcription of genes encoding enzymes in aliphatic and indolic glucosinolate pathways were detected. Quantitative real-time RT-PCR was performed using Trans Start Top Green qPCR Supermix on an ABI 7500 sequence detection system (Takara). The selected genes and primers used are listed in Table 1 Suppl. The AtACTIN-2 gene was used as an internal control. Transcription of the genes was calculated with the $2^{-\Delta \Delta \mathrm{CT}}$ method. To enable statistical analysis, three independent biological replicates and three technical repeats were conducted. To determine whether the responsive expression pattern of $B o C Y P 83 B 1$ observed in $P_{B о C Y P 83 B 1} \because G U S$ transgenic Arabidopsis represents that in broccoli, expressions of $B o C Y P 83 B 1$ in broccoli under the different treatments were detected as described above using primers BoCYP83B1-QRT-F and BoCYP83B1-QRT-R (Table 1 Suppl.). The BoACTIN-2 gene in broccoli was used as an internal control.

leaves of the broccoli cv. Qingxiu. A BLAST search (Altschul et al. 1990) revealed that the CDS of the 


\section{R. XU et al.}

obtained gene shared a high sequence similarity with the other Brassicaceae, including $90 \%$ identity with CYP83B1 of Arabidopsis and $99 \%$ identity with B. napus and $B$. rapa. Therefore, we named the obtained gene BoCYP83B1 (GenBank accession no. KU559565). The full-length mRNA of BoCYP83B1 was 1795 bp and

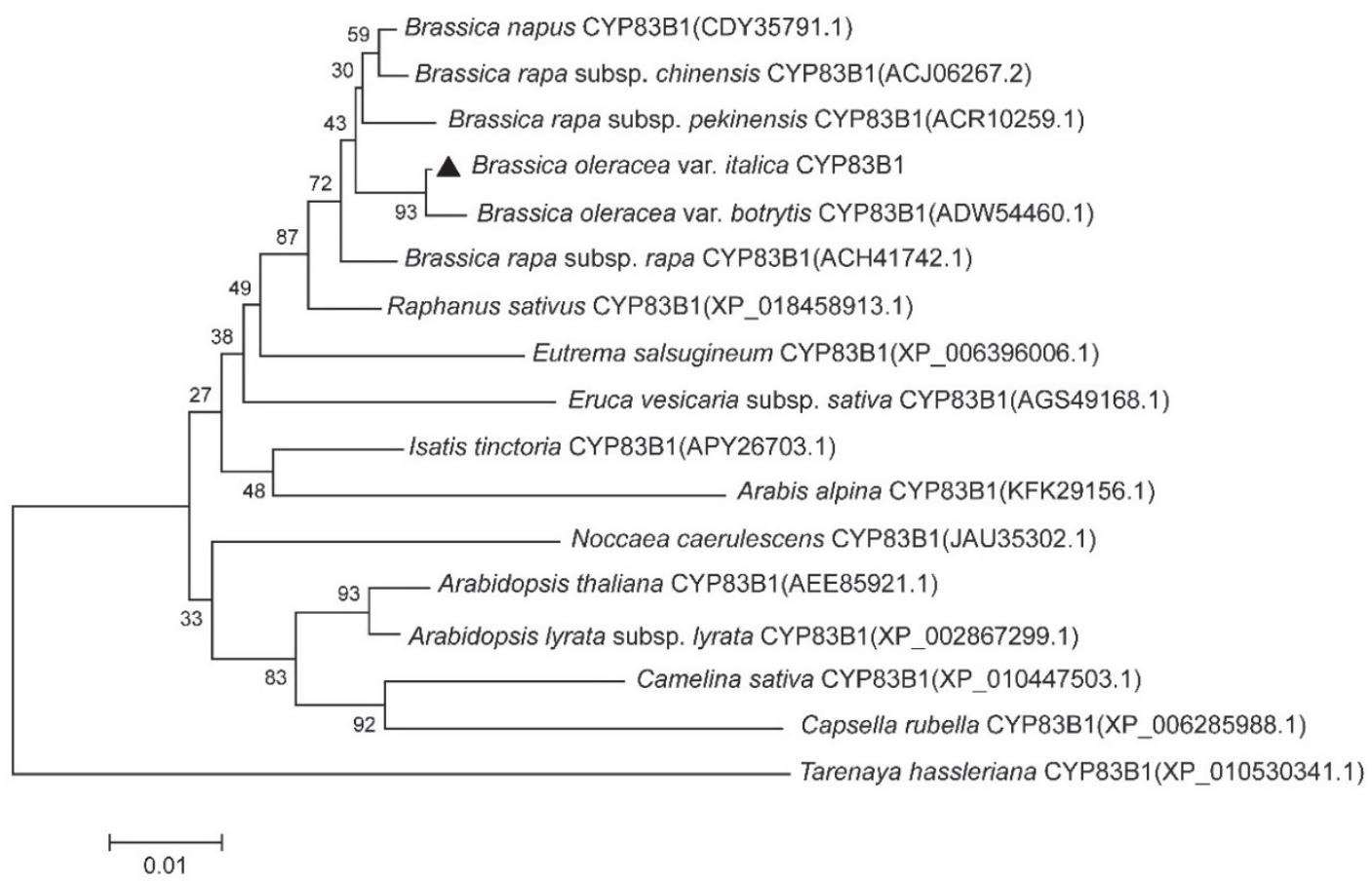

Fig. 1. Evolutionary relationships between BoCYP83B1 proteins. Phylogenetic analysis of BoCYP83B1 with its orthologs from Brassicaceae plants which share more than $90 \%$ sequence similarity was performed using the neighbor-joining method in the MEGA 5.0. The percentage of replicate trees in which the associated proteins clustered together in the bootstrap test (1 000 replicates) is shown next to the branches. The tree is drawn to scale, with branch lengths measured in the number of substitutions per site.
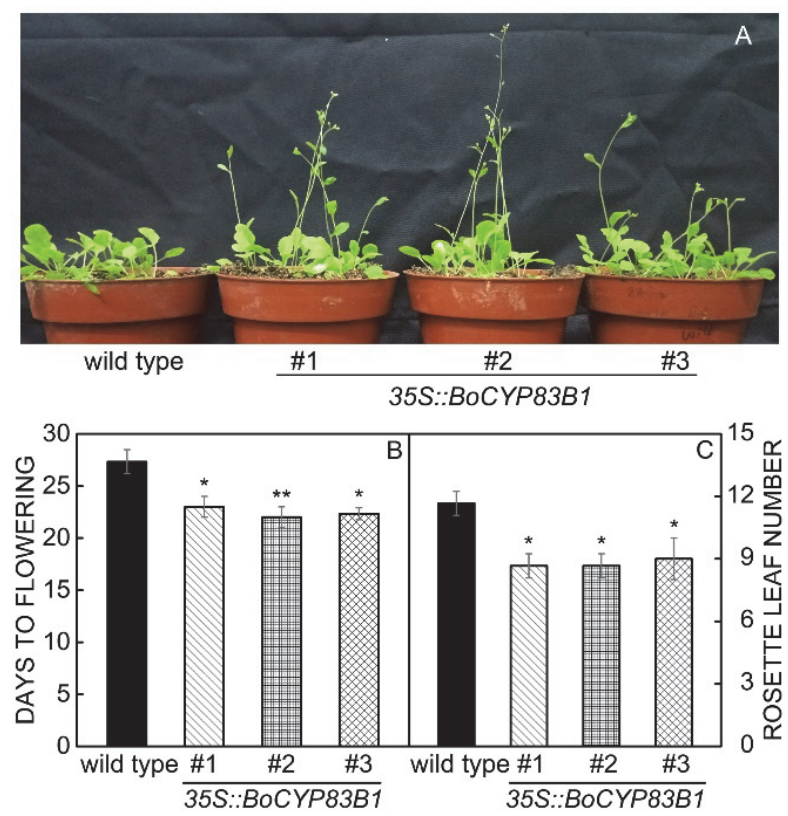

Fig. 2. The BoCYP83B1 overexpression promotes flowering in Arabidopsis. A - Flowering phenotype of wild type and $35 S:: B o C Y P 83 B 1$ plants under a 16-h photoperiod. $B$ - Average flowering time (days after germination). $C$ - The average number of rosette leaves at the time of flowering. Three independent $35 S:: B o C Y P 83 B 1$ transgenic lines (\#1, \#2, and \#3) were confirmed by reverse transcription PCR. All values in $B$ and $C$ are means \pm SEs from three independent experiments (10 seedlings per experiment); * and $* *$ indicate significant differences from the corresponding wild type at $0.01<P<0.05$ and $P<0.01$, respectively ( $t$-test). 
contained a 23-bp 5' untranslated region (UTR), a 272-bp 3'-UTR and a 1 500-bp CDS encoding 499 amino acids. Multiple alignment of the deduced BoCYP83B1 with its orthologs from Brassicaceae plants indicates that BoCYP83B1 showed a high similarity with other proteins (Fig. 1 Suppl.).

To investigate evolutionary relationships, all the CYP83B1 proteins with available sequences in the Brassicaceae family were applied for phylogenetic analysis using CYP83B1 from Tarenaya hassleriana of the Cleomaceae family as an outgroup. As shown in Fig. 1, all the CYP83B1 proteins were tightly clustered together with the exception of CYP83B1 from Tarenaya hassleriana. The CYP83B1 proteins were clustered into two clades, which is consistent with the previously identified phylogenesis of Brassicaceae (Warwick et al. 2006). All CYP83B1s from the Brassica genus formed a subclade. The closest related protein to BoCYP83B1 was
CYP83B1 in B. oleracea var. botrytis.

The physicochemical properties, hydrophilicity/ hydrophobicity and a 3D structure model of BoCYP83B1 were predicted by Protparam, ProtScale, and Swiss-Model, respectively (Fig. 2 Suppl. and Table 2 Suppl.). Analysis using TMHMM, NetPhos2.0Server, SOPMA, and SMART suggests that BoCYP83B1 had potentially the following characteristics: not a transmembrane protein contained 16 phosphorylation sites, the most abundant secondary structure was an $\alpha$-helix and inclusion of a typical P450 domain (Fig. 2 Suppl.).

In 35S::BoCYP83B1 transgenic Arabidopsis (overexpression of $B o C Y P 83 B 1$ was confirmed by RT-PCR, Fig. 3 Suppl.), an early flowering phenotype was observed (Fig. 2A). Comparing to the wild type, 35S::BoCYP83B1 plants flowered about $5 \mathrm{~d}$ earlier when they had less leaves than the wild type (Fig. 2B,C). This result is consistent with a previous study in which an early flowering
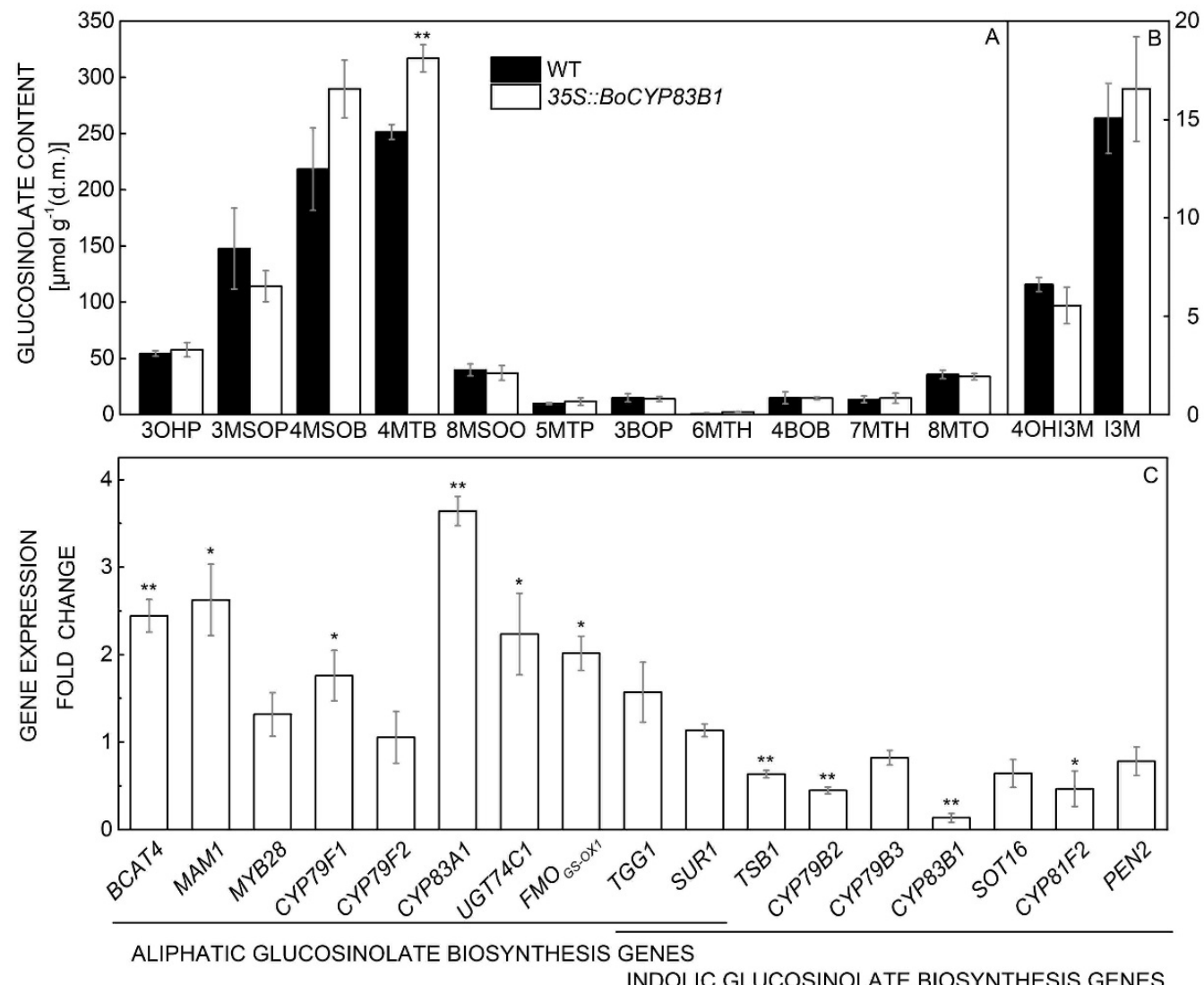

Fig. 3. Glucosinolate content analyzed by HPLC and expression of glucosinolate metabolism pathway genes in $35 S:: B o C Y P 83 B 1$. $A$ - Aliphatic glucosinolate content in seeds. $B$ - Indolic glucosinolate content in seeds. 3OHP - 3-hydroxylpropyl glucosinolate; 3BOP - 3-benzoylpropyl glucosinolate; 3MSOP - 3-methylsulphinylpropyl glucosinolate; 4BOB - 4-benzoylbutyl glucosinolate; 4MSOB - 4-methylsulphinylbutyl glucosinolate; 4MTB - 4-methylthiobutyl glucosinolate; 5MTP - 5-methylthiopentyl glucosinolate; 6MTH - 6-methylthiohexyl glucosinolate; 7MTH - 7-methylthiohepthyl glucosinolate; 8MSOO - 8-methylsulphinyloctyl glucosinolate; 8MTO - 8-methylthiooctyl glucosinolate; 4OHI3M - 4-hydroxyindol-3-ylmethyl glucosinolate; I3M - indol-3-ylmethyl glucosinolate. $C$ - The fold change of gene expression in seedlings of wild type and 35S::BoCYP83B1 transgenic Arabidopsis plants determined by real time reverse transcription PCR. For $A, B$ and $C$, three independent transgenic lines confirmed with a high expression level of $B o C Y P 83 B 1$ and a clear phenotype was used. The experiment included three biological repeats and three technical repeats; means \pm SEs are shown; * and ** indicate significant differences from the corresponding wild type at $0.01<P<0.05$ and $P<0.01$, respectively ( $t$-test). 
phenotype was observed in Arabidopsis overexpressing its own CYP83B1 gene (Naur et al. 2003). The substrate of CYP83B1, IAOx, is also a precursor of IAA, thus, it is expected that consumption of IAOx by BoCYP83BI overexpression results in decrease of IAA. However, no significant alteration of IAA content was detected in
35S::BoCYP83B1 (Fig. 4 Suppl.). This indicates that the deficit of IAOx derived IAA was possibly compensated by balancing other IAA biosynthesis pathways. Thus, the early flowering phenotype was probably induced by other factors instead of IAA.

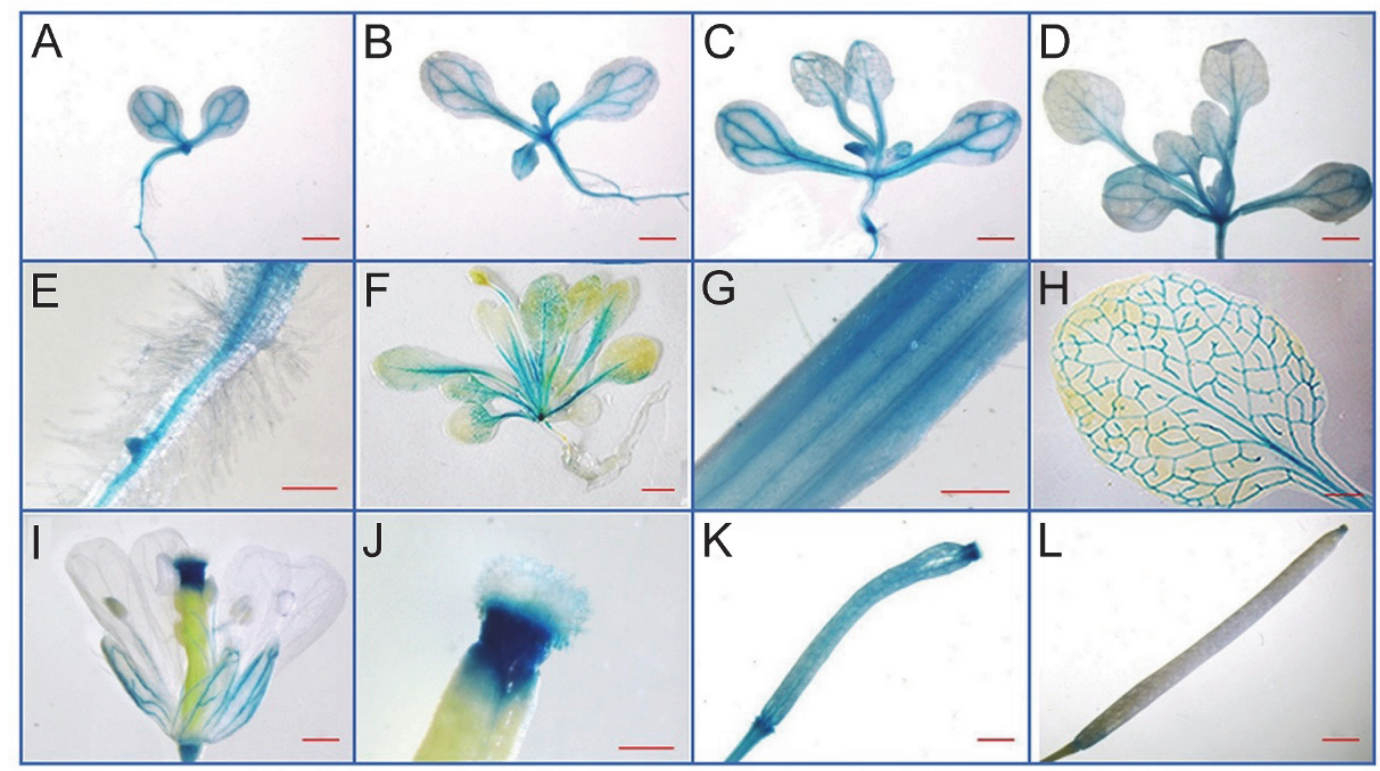

Fig. 4. The spatial pattern of $B o C Y P 83 B 1$. The $B o C Y P 83 B 1$ expression was analyzed by detecting $\beta$-glucuronidase (GUS) activity in transgenic plants expressing $B o C Y P 83 B 1$ promoter-directed $G U S$. $A$ - cotyledon stage; $B$ - two-leaf stage; $C$ - four-leaf stage; $D$ - six-leaf stage; $E$ - root; $F$ - mature plant; $G$ - flower stalk; $H$ - mature leaf; $I$ - flower; $J$ - stigma; $K$ - immature silique; $L$ - mature silique. Bars $=1 \mathrm{~mm}(A, B, C, D, K, L) ; 0.25 \mathrm{~mm}(E, J) ; 0.5 \mathrm{~cm}(F) ; 0.5 \mathrm{~mm}(G, I) ; 1.5 \mathrm{~mm}(H)$.

To determine the catalytic function of BoCYP83B1, glucosinolate content was detected in $35 S:: B o C Y P 83 B 1$. To minimize possible maternal effects, heterozygous transgenic lines with the confirmed high expression of $B o C Y P 83 B 1$ and the early flowering phenotype were selected, and the glucosinolate content was detected in the leaves and seeds of the segregating progeny obtained from the heterozygous transgenic parents. No significant change in glucosinolate accumulation was detected in the leaves (Fig. 5 Suppl.). In the seeds, the content of indolic glucosinolates was also comparable to the wild type plant, whereas the content of aliphatic glucosinolates was higher in $35 S:: B o C Y P 83 B 1$ than in the wild type. The increased content of aliphatic glucosinolates was primarily due to a significantly increased accumulation of 4-methylthiobutyl glucosinolate (Fig. 3A). This result was quite unexpected since AtCYP83B1 has been demonstrated to be an enzyme metabolizing IAOx to corresponding S-alkyl-thiohydroximates, which is a part of indolic glucosinolate biosynthetic pathway (Bak et al. 2001). However, similar results were shown in several other reports. Naur et al. (2003) showed that overexpression of $A t C Y P 83 B 1$ in Arabidopsis leads to a higher accumulation of aliphatic glucosinolates without significantly increasing content of indolic glucosinolates. Zang et al. (2008) overexpressed
AtCYP83B1 in Chinese cabbage, but they did not observe any alteration in content of indolic glucosinolates. One possible explanation for this discrepancy is that BoCYP83B1 overexpression caused rebalancing the whole biosynthetic pathway. To validate this hypothesis, transcriptions of genes in the glucosinolate metabolism pathway were detected. As shown in Fig. $3 B$, in the $35 S:: B o C Y P 83 B 1$ transgenic Arabidopsis, a half of the genes in the indolic glucosinolate pathway including AtCYP83B1 were significantly down-regulated, and a half of the genes in the aliphatic pathway were up-regulated. These results explain the glucosinolate phenotype in $35 S:: B o C Y P 83 B 1$ and indicate that IAOx catalysis is not a rate-limiting step in the indolic glucosinolate biosynthesis pathway.

Based on the facts that BoCYP83B1 shared a high sequence similarity with its ortholog AtCYP83B1, contained the same P450 function domain, and overexpression of the two CYP83B1 genes in the transgenic plants presented a similar morphological phenotype and glucosinolate profile, we speculate that BoCYP83B1 has a similar enzyme catalytic activity as its Arabidopsis ortholog.

To investigate the spatial expression pattern of $B o C Y P 83 B 1$, a $2 \mathrm{~kb}$ fragment upstream of the $B o C Y P 83 B 1$ 
start codon was amplified from the genomic DNA as the promoter. The transgenic plants $P_{\text {BoCYP83B1 }}: G U S$, which expressed GUS under control of the $B o C Y P 83 B 1$ promoter, were generated. Promoter activity was detected by the GUS signal in vivo. In seedlings at cotyledon, two-leaf, four-leaf, and six-leaf stages, the GUS signals were detected in the vascular tissue of radicles, hypocotyls, cotyledons, leaves, and roots (Fig. $4 A, B, C, D$ ). In the root, $B o C Y P 83 B 1$ was expressed during the seedling stage in the vascular cylinder, and a high expression was observed in the lateral root primordium (Fig. $4 E$ ). In the adult plants, GUS activity was predominantly detected in the vascular tissue of the petioles, flower stalks, and leaf veins, and hardly any GUS signal was observed in the roots (Fig. 4F). In flower stalks, GUS staining was observed in the vascular bundle and the middle of the pitch (Fig. 4G). In the mature leaf, the GUS signal was clearly observed in the mid-vein and more or less in the side veins (Fig. 4H). As concerns the reproductive organs, GUS activity was detected in the vascular tissue of the sepals and the filaments of the stamen, and an extremely strong GUS signal was present in the style of the pistil (Fig. 4I,J). In the silique, BoCYP83B1 was expressed in the young carpels but not in the mature carpels (Fig. $4 K, L$ ).

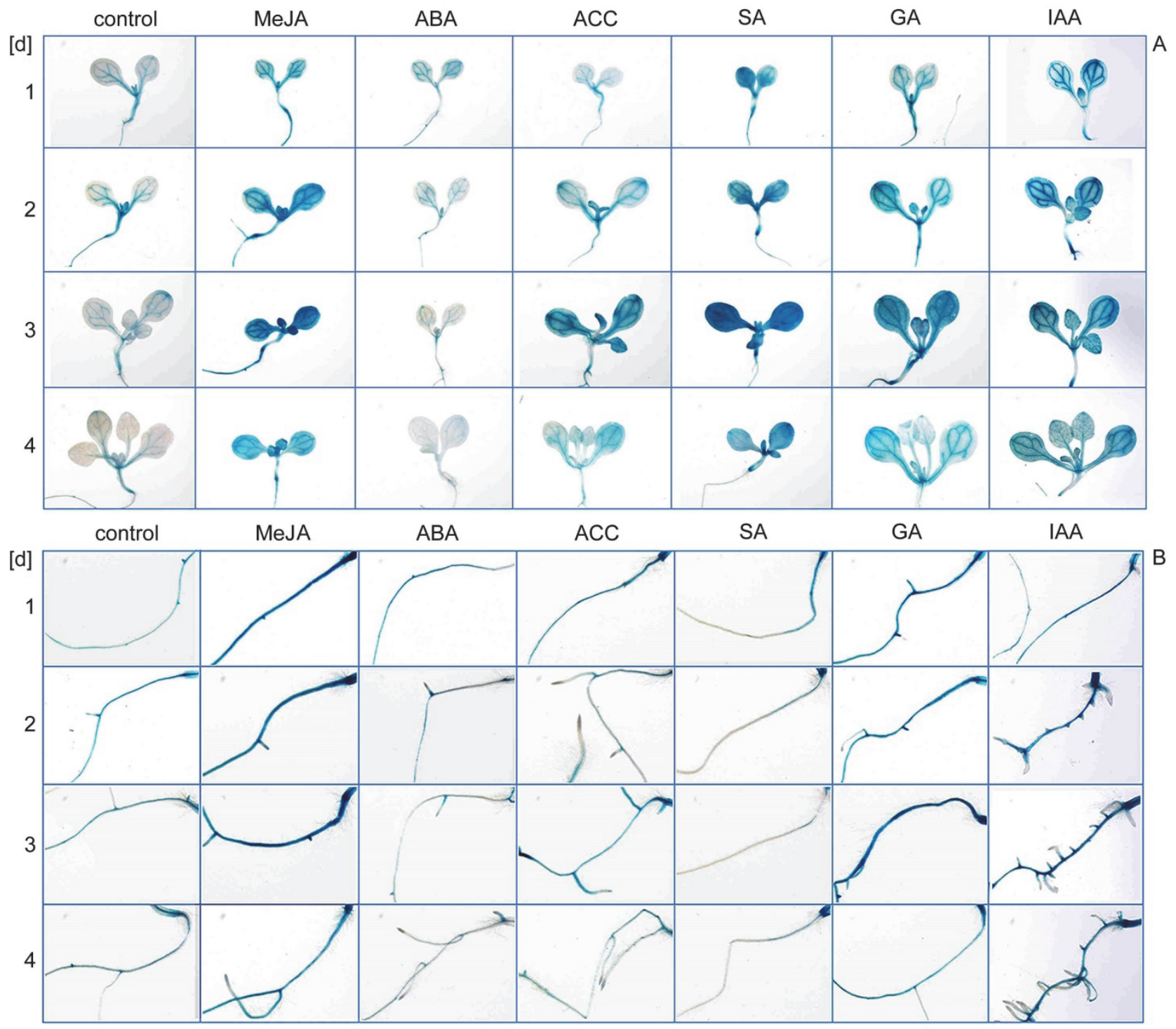

Fig. 5. Expression of $B o C Y P 83 B 1$ in response to phytohormones. $A$ - BoCYP83B1 expression in leaves. $B$ - BoCYP83B1 expression in roots. Five-d-old plants were transferred to $1 / 2 \mathrm{MS}$ agar media containing $25 \mu \mathrm{M}$ methyl jasmonate (MeJA), $200 \mu \mathrm{M}$ salicylic acid (SA), $10 \mu \mathrm{M}$ abscisic acid (ABA), $20 \mu \mathrm{M}$ 1-amino-1-cyclopropanecarboxylic acid (ACC), $10 \mu \mathrm{M}$ gibberellic acid (GA), or $5 \mu \mathrm{M}$ indole-3-acetic acid (IAA) and grown for $4 \mathrm{~d}$. Plants transferred to the $1 / 2 \mathrm{MS}$ agar medium without hormone addition were used as a control. Activity of $\beta$-glucuronidase (GUS) was detected at the same time each day. Three independent transgenic lines were used for GUS activity analysis. All the transgenic lines showed a similar staining pattern and responding tendency. The result (repeated three times) of one line is shown. 
R. XU et al.
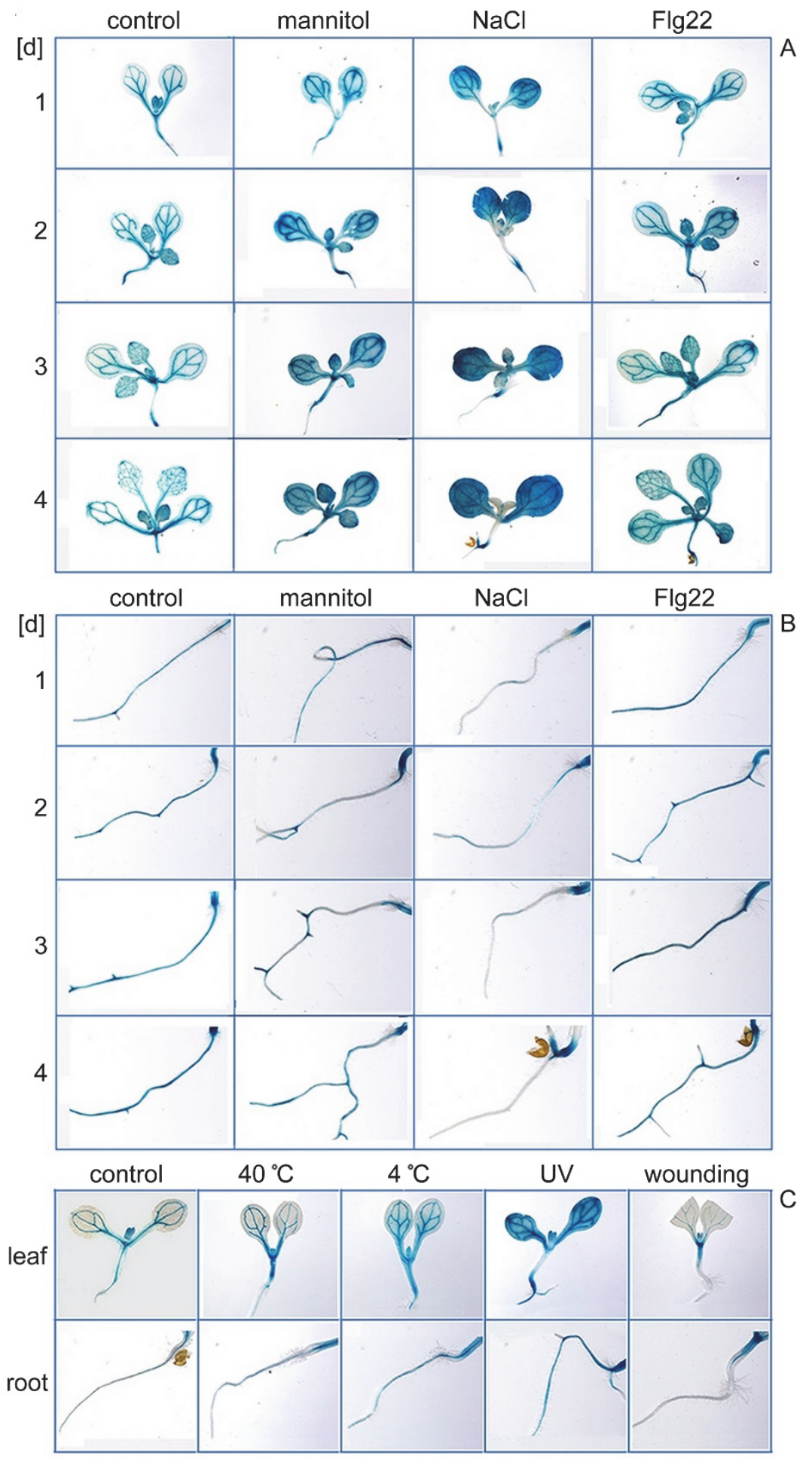

Fig. 6. Expression of $B o C Y P 83 B 1$ in response to different stresses. $A$ - BoCYP83B1 expression in leaves in response to mannitol, NaCl and Flagelin 22 (Flg22). $B$ - BoCYP83B1 expression in roots in response to mannitol, $\mathrm{NaCl}$ and $\mathrm{Flg} 22$. $C$ - BoCYP83B1 expression in response to a high temperature, a low temperature, UV, and wounding. 5-d-old plants were transferred to 1/2 MS agar media containing $200 \mathrm{mM}$ mannitol, $150 \mathrm{mM} \mathrm{NaCl}$, or $1 \mu \mathrm{M}$ Flg22 and grown for $4 \mathrm{~d}$. Activity of $\beta$-glucuronidase (GUS) was detected at the same time each day during treatment. For the other stress treatments, 5-d-old plants were exposed to UV radiation for $1.5 \mathrm{~h}, 40{ }^{\circ} \mathrm{C}$ for $2 \mathrm{~h}$, and $4{ }^{\circ} \mathrm{C}$ for $2 \mathrm{~h}$. The wounding treatment was performed by cutting the cotyledons in half. Seedlings without any treatment were used as a control. Three independent transgenic lines were used for GUS activity analysis. All the transgenic lines showed a similar staining pattern and responding tendency. 
To better understand how environmental factors affect the catalysis of IAOx by BoCYP83B1 and to identify related signaling pathways where BoCYP83B1 is involved, we evaluated the response of $B o C Y P 83 B 1$ expression to different environmental conditions and treatments with plant hormones. Firstly, the promoter sequence of BoCYP83B1 was analyzed with PlantCARE (bioinformatics.psb.ugent.be/webtools/plantcare/html/) to identify potential cis-elements. Several hormone responsive elements and stress-related elements were found (Table 3 Suppl.). To investigate whether BoCYP83B1 responded to these biotic and abiotic stresses and was involved in predicted hormone signaling pathways, 5-d-old seedlings of the transgenic plant expressing $P_{\text {BoCYP83B }} \because \because G U S$ were treated with MeJA, SA, ABA, ACC, GA, and IAA, and a series of abiotic and biotic stresses including $\mathrm{NaCl}$, mannitol, $40{ }^{\circ} \mathrm{C}, 4^{\circ} \mathrm{C}$, UV, wounding, and a plant bacterial defense elicitor Flg22. The expression of BoCYP83B1 was evaluated according to GUS staining in vivo (Figs. 5 and 6) and a quantitative assay of GUS activity in the seedlings (Fig. 6 Suppl.).

After 4-d treatments, BoCYP83B1 expression was significantly affected by all hormones except ABA (Fig. $5 A$ and Fig. 6 Suppl.). The MeJA, ACC, SA, GA, and IAA strongly induced $B o C Y P 83 B 1$ in the shoots, and the induction steadily increased over the first $3 \mathrm{~d}$. The induction began to weaken on the fourth day. The BoCYP83B1 did not appear to be very sensitive to ABA because only a slight inhibition was observed after $4 \mathrm{~d}$ of ABA treatment. In the roots, the effect of these hormones resembled the effects observed in the shoots, except for SA (Fig. 5B). In contrast to a strongly induced expression of $B o C Y P 83 B 1$ in the shoots, SA significantly inhibited $B o C Y P 83 B 1$ expression in the roots (Fig. 5B). The organ specific responses of $B o C Y P 83 B 1$ indicate that BoCYP83B1 might play different roles in different organs in response to $\mathrm{SA}$. In addition to affecting $B o C Y P 83 B 1$ expression, MeJA, ABA, and SA largely inhibited growth and development of the seedlings. After $4 \mathrm{~d}$, the control seedlings and those treated with ACC, GA, and IAA had four leaves, whereas the seedlings treated with MeJA, ABA, and SA had only two small euphyllas. The SA treatment inhibited formation of lateral roots, whereas IAA significantly promoted formation of them (Fig. $5 B$ ). Under stress treatments, BoCYP83B1 was continually induced by mannitol, $\mathrm{NaCl}$, and Flg22 in the shoots, but no significant induction was observed in the roots (Fig. 6A,B). Interestingly, a strong $B o C Y P 83 B 1$ expression activated by $\mathrm{NaCl}$ was observed only in the cotyledons and the junction of the hypocotyl and root (Fig. 6A,B). However, $B o C Y P 83 B 1$ expression was significantly inhibited in the emerging euphyllas, hypocotyl, and roots in response to $\mathrm{NaCl}$ (Fig. 6A,B and Fig. 7 Suppl.). This tissue-specific expression pattern was quite similar when the plant was treated with SA.

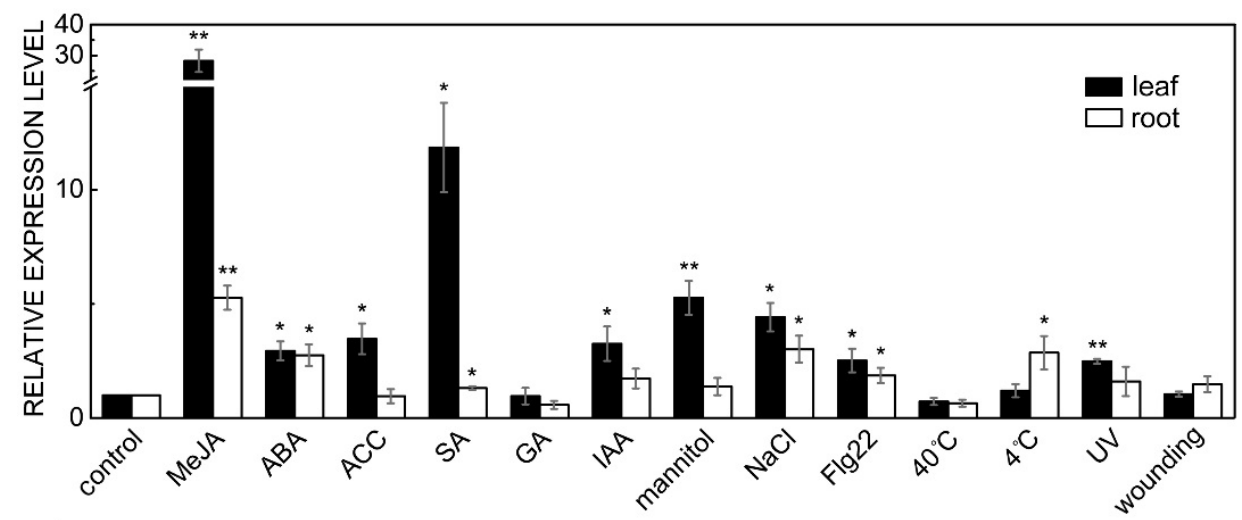

Fig. 7. Expression of $B o C Y P 83 B 1$ in response to exogenous hormones and stresses in broccoli. Transcription of $B o C Y P 83 B 1$ was determined by real time reverse transcription PCR. 5-d-old seedlings were treated as described above. The experiment included three biological repeats, and three technical repeats; mean values $( \pm \mathrm{SEs})$ are shown. Data were analyzed statistically using the $t$-test, $*$ and ** indicate significant differences from the corresponding control at $0.01<P<0.05$ and $P<0.01$, respectively.

Because treatment with high temperature $\left(40^{\circ} \mathrm{C}\right)$, low temperature $\left(4{ }^{\circ} \mathrm{C}\right)$, UV radiation and wounding causes wilting, no time course experiments were performed. As shown in Fig. 6C, BoCYP83B1 was significantly induced by UV radiation and slightly enhanced by a high or low temperature. A position-specific responsive expression pattern to wounding was again observed. After the cotyledons were cut in half, a condensed GUS signal was observed at the cotyledonary node suggesting a strong expression of BoCYP83B1, whereas expression was inhibited in the cotyledons and roots.

The expression pattern of BoCYP83B1 presented by GUS staining was confirmed and quantified by quantitative analysis of GUS activity in the seedlings of the transgenic plant $P_{B о C Y P 83 B I}: \because G U S$. Activity of GUS significantly increased after all the treatments except ABA (Fig. 6 Suppl.), which is perfectly consistent with the results obtained from GUS staining.

To determine whether the expression pattern of BoCYP83B1 observed in Arabidopsis represents that in 
broccoli, quantitative real time PCR was performed in broccoli. The 5-d-old broccoli seedlings were treated as described above and transcriptions of $B o C Y P 83 B 1$ in the leaves and roots were detected (Fig. 7). Consistently MeJA, ACC, SA, IAA, mannitol, $\mathrm{NaCl}$, Flg22, and UV significantly up-regulated $B o C Y P 83 B 1$ expression in the leaves as observed in Arabidopsis. Comparing to the leaves, BoCYP83B1 expression seemed to be less affected by all the treatments in the roots, and the responsive expression pattern basically coincided with that shown in Arabidopsis. Driven by the promoter of BoCYP83B1, GUS transcription in Arabidopsis can largely represent the BoCYP83B1 expression in broccoli. However, some differences were found between the observations in Arabidopsis and broccoli. In Arabidopsis, GUS expression driven by the $B o C Y P 83 B 1$ promotor was slightly repressed by $\mathrm{ABA}$ and significantly induced by GA, whereas in broccoli, BoCYP83B1 expression was promoted by ABA and not affected by GA. For both Arabidopsis and broccoli, the 5-d-old seedlings were used in gene expression analysis. They were not possibly in the perfectly equivalent development stage, and therefore responded to the same stimuli differently. Another possibility is that the regulatory proteins controlling BoCYP83B1 promoter activity in Arabidopsis are not completely identical with those in broccoli. Comparing to GUS activity observed in transgenic Arabidopsis $P_{\text {BoCYP83B } 1}: G U S$, transcription level detected in broccoli can represent the expression of BoCYP83B1 more authentically. However, the transcription level is not as visualized as GUS signal presented in the image and thus may lose some detailed information.

In this study, we isolated the broccoli $B o C Y P 83 B 1$ gene, which was an ortholog of the Arabidopsis CYP83B1. Phylogenetic analysis proved that the CYP83B1s were highly conserved in Brassicaceae plants. In Arabidopsis, CYP83B1 has been shown to catalyze conversion of aromatic oximes derived from Phe, Trp, and Tyr to corresponding S-alkyl-thiohydroximates and further to indolic glucosinolates (Bak and Feyereisen 2001, Bak et al. 2001, Hansen et al. 2001). However, BoCYP83B1 overexpression in Arabidopsis did not result in an increased production of indolic glucosinolates, which was unexpected. However, this result is consistent with a previous study in which transgenic Arabidopsis overexpressing AtCYP83B1 showed an indolic glucosinolate content similar to that in a wild type (Naur et al. 2003). Similar results were found in other studies. For instance, overexpression of CYP83B1 alone in Chinese cabbage does not affect indolic glucosinolate accumulation, whereas overexpression of $C Y P 83 B 1$ together with genes $C Y P 79 B 2$ or $C Y P 79 B 3$ significantly increases indolic glucosinolate biosynthesis (Zang et al. 2008). Based on these studies, we speculate that CYP83B1 is not a rate-limiting enzyme in indolic glucosinolate production.

Interestingly, the $35 S:: B o C Y P 83 B 1$ transgenic
Arabidopsis showed an increased content of aliphatic glucosinolates. This can possibly be explained by promoted expressions of genes encoding several enzymes concerning aliphatic glucosinolate biosynthesis in the $35 S:: B o C Y P 83 B 1$ transgenic plants. Another explanation is that BoCYP83B1 likely catalyzes an aliphatic oxime and promotes production of aliphatic glucosinolates. In Arabidopsis, aliphatic oximes derived from methionine are thought to be metabolized by CYP83A1 rather than by CYP83B1 (Bak and Feyereisen 2001, Hemm et al. 2003, Naur et al. 2003). However, CYP83B1 metabolizes the aliphatic oximes with a low efficiency (Bak and Feyereisen 2001, Hemm et al. 2003). Considering that content of aliphatic glucosinolates is much higher than that of indolic glucosinolates, the excessive BoCYP83B1 in $35 S:: B o C Y P 83 B 1$ could possibly choose aliphatic oximes with higher concentrations as substrates and promote aliphatic glucosinolate production.

In Arabidopsis, CYP83B1 is functional as a repressor of IAA biosynthesis due to consumption of IAOx, which is the common intermediate of IAA and indolic glucosinolates. Thus, CYP83B1 is involved in many aspects of growth and development (Barlier et al. 2000, Mikkelsen et al. 2000, Bak et al. 2001, Smolen and Bender 2002). A knock-out mutant of CYP83B1 (sur2-8) presents a severe high-auxin "supperroot" phenotype (Delarue et al. 1998, Barlier et al. 2000, Bak and Feyereisen 2001, Bak et al. 2001, Naur et al. 2003). A missense mutation with a one amino acid change in CYP83B1 lead to a tall phenotype due to the long hypocotyl (Maharjan et al. 2014). The CYP83B1 can also be involved in stem branching through regulation of auxin homeostasis under a high ratio of red to far-red radiation (Hoecker et al. 2004, Zhang et al. 2014). However, whether the IAOx-dependent IAA biosynthesis pathway is conserved in broccoli and whether BoCYP83B1 is involved in plant growth and development are unknown. Our study shows that $B o C Y P 83 B 1$ was not only induced by MeJA and SA, which suggests its function in biotic stress resistance, but it was also strongly induced by IAA and GA, indicating that $B o C Y P 83 B 1$ is possibly involved in growth and development.

The expression pattern analysis shows that $B o C Y P 83 B 1$ was expressed in the roots, leaves, flower stalks, flowers, sepals, pistils, stigma, and young siliques. This expression pattern was quite similar to that of AtCYP83B1 (Mizutani et al. 1998, Barlier et al. 2000, Maharjan et al. 2014), suggesting the conservation of promoter elements between the two orthologs. The BoCYP83B1 was found to be responsive to several hormones, which are closely related to stress resistance and plant development. The BoCYP83B1 was strongly induced by MeJA, SA, ACC, GA, and IAA, and slightly repressed by ABA. These responses indicate that $B o C Y P 83 B 1$ is involved in complex signal transduction pathways and support a suggestion that like its Arabidopsis ortholog, BoCYP83B1 plays a role not only 
in defense against pathogens and herbivores but also in plant growth and development.

In Arabidopsis, biosynthesis of indolic glucosinolates is affected by many environmental factors, especially biotic and abiotic stresses (Mikkelsen et al. 2003, Mewis et al. 2005, 2006, 2012 Alvarez et al. 2008, Pfalz et al. 2009). Consistently, cis-acting elements involved in defense and stress responses were found in the promoter sequence of $B o C Y P 83 B 1$. Therefore, we detected expression of $B o C Y P 83 B 1$ in response to several biotic and abiotic stresses. Under our experimental conditions, BoCYP83B1 was strongly induced by treatments with mannitol, $\mathrm{NaCl}$, Flg22, and UV radiation.

Although BoCYP83B1 has the same catalytic activity as AtCYP83B1, it displays distinctive expression patterns. In Arabidopsis, CYP83B1 has been reported to be preferentially expressed in roots and induced by wounding (Mizutani et al. 1998, Reymond et al. 2000). Conversely, $B o C Y P 83 B 1$ was preferentially expressed in the shoots. When challenged with wounding, BoCYP83B1 expression in the cotyledons and roots decreased. However,

\section{References}

Agerbirk, N., Olsen, C.E.: Glucosinolate structures in evolution. - Phytochemistry 77: 16-45, 2012.

Altschul, S.F., Gish, W., Miller, W., Myers, E.W., Lipman, D.J.: Basic local alignment search tool. - J. mol. Biol. 215: 403-410, 1990

Alvarez, S., He, Y., Chen, S.: Comparative investigations of the glucosinolate-myrosinase system in Arabidopsis suspension cells and hypocotyls. - Plant Cell Physiol. 49: 324-333, 2008.

Andersson, M.X., Nilsson, A.K., Johansson, O.N., Boztas, G., Adolfsson, L.E., Pinosa, F., Petit, C.G., Aronsson, H., Mackey, D., Tor, M., Hamberg, M., Ellerstrom, M.: Involvement of the electrophilic isothiocyanate sulforaphane in Arabidopsis local defense responses. - Plant Physiol. 167: 251-261, 2015.

Ares, A.M., Nozal, M.J., Bernal, J.: Extraction, chemical characterization and biological activity determination of broccoli health promoting compounds. - J. Chromatogr. A 1313: 78-95, 2013.

Bak, S., Feyereisen, R.: The involvement of two p450 enzymes, CYP83B1 and CYP83A1, in auxin homeostasis and glucosinolate biosynthesis. - Plant Physiol. 127: 108-118, 2001.

Bak, S., Tax, F.E., Feldmann, K.A., Galbraith, D.W., Feyereisen, R.: CYP83B1, a cytochrome P450 at the metabolic branch point in auxin and indole glucosinolate biosynthesis in Arabidopsis. - Plant Cell 13: 101-111, 2001.

Barlier, I., Kowalczyk, M., Marchant, A., Ljung, K., Bhalerao, R., Bennett, M., Sandberg, G., Bellini, C.: The SUR2 gene of Arabidopsis thaliana encodes the cytochrome P450 CYP83B1, a modulator of auxin homeostasis. - Proc. nat. Acad. Sci. USA 97: 14819-14824, 2000.

Bednarek, P., Osbourn, A.: Plant-microbe interactions: chemical diversity in plant defense. - Science 324: 746-748, 2009.

Bhuria, M., Goel, P., Kumar, S., Singh, A.K.: The promoter of AtUSP is co-regulated by phytohormones and abiotic stresses
BoCYP83B1 was significantly induced by SA in the cotyledons and emerging euphyllas, but it was largely repressed in the roots. When treated with $\mathrm{NaCl}$, BoCYP83B1 expression was strongly induced in the cotyledons but significantly repressed in the emerging euphyllas, hypocotyls, and in roots, expression appeared to be highly concentrated at the junction of the radicle and hypocotyl. Since CYP83B1 affects production of several different metabolites, indolic glucosinolates, camalexin, and IAA, this gene may execute different functions in different cells.

In summary, we identified a $B o C Y P 83 B 1$ gene from broccoli and analyzed its expression pattern. Since the substrate of CYP83B1 (IAOx) is a precursor of important natural products and the plant hormone auxin, the gene should be studied in economically relevant vegetables as well as in model plants. In this study, we present abundant data concerning the BoCYP83B1 expression pattern, which will provide useful information and further understanding the function and regulation of this gene in broccoli.

in Arabidopsis thaliana. - Front. Plant Sci. 7: 1957, 2016.

Biasini, M., Bienert, S., Waterhouse, A., Arnold, K., Studer, G., Schmidt, T., Kiefer, F., Cassarino, T.G., Bertoni, M., Bordoli, L., Schwede, T.: SWISS-MODEL: modelling protein tertiary and quaternary structure using evolutionary information. Nucl. Acids Res. 42: W252-W258, 2014.

Blom, N., Gammeltoft, S., Brunak, S.: Sequence and structure-based prediction of eukaryotic protein phosphorylation sites. - J. mol. Biol. 294: 1351-1362, 1999.

Chen, Y.J., Yu, P., Luo, J.C., Jiang, Y.: Secreted protein prediction system combining CJ-SPHMM, TMHMM, and PSORT. - Mammalian Genome 14: 859-865, 2003.

Clay, N.K., Adio, A.M., Denoux, C., Jander, G., Ausubel, F.M.: Glucosinolate metabolites required for an Arabidopsis innate immune response. - Science 323: 95-101, 2009.

Clough, S.J., Bent, A.F.: Floral dip: a simplified method for Agrobacterium-mediated transformation of Arabidopsis thaliana. - Plant J. 16: 735-743, 1998.

Delarue, M., Prinsen, E., Onckelen, H.V., Caboche, M., Bellini, C.: Sur2 mutations of Arabidopsis thaliana define a new locus involved in the control of auxin homeostasis. - Plant J. 14: 603-611, 1998.

Fahey, J.W., Haristoy, X., Dolan, P.M., Kensler, T.W., Scholtus, I., Stephenson, K.K., Talalay, P., Lozniewski, A.: Sulforaphane inhibits extracellular, intracellular, and antibiotic-resistant strains of Helicobacter pylori and prevents benzo a pyrene-induced stomach tumors. - Proc. nat. Acad. Sci. USA 99: 7610-7615, 2002.

Fahey, J.W., Zhang, Y., Talalay, P.: Broccoli sprouts: an exceptionally rich source of inducers of enzymes that protect against chemical carcinogens. - Proc. nat. Acad. Sci. USA 94: 10367-10372, 1997.

Frerigmann, H., Pislewska-Bednarek, M., Sanchez-Vallet, A., Molina, A., Glawischnig, E., Gigolashvili, T., Bednarek, P.: Regulation of pathogen-triggered tryptophan metabolism in 
Arabidopsis thaliana by MYB transcription factors and indole glucosinolate conversion products. - Mol. Plant 9: 682-695, 2016.

Gasteiger, E., Gattiker, A., Hoogland, C., Ivanyi, I., Appel, R.D., Bairoch, A.: ExPASy: the proteomics server for in-depth protein knowledge and analysis. - Nucl. Acids Res. 31: 3784-3788, 2003.

Geourjon, C., Deleage, G.: SOPMA: significant improvements in protein secondary structure prediction by consensus prediction from multiple alignments. - C.A.B.I.O.S. 11: 681-684, 1995.

Geu-Flores, F., Nielsen, M.T., Nafisi, M., Moldrup, M.E., Olsen, C.E., Motawia, M.S., Halkier, B.A.: Glucosinolate engineering identifies gamma-glutamyl peptidase. - Nat. chem. Biol. 5: 575-577, 2009.

Grubb, C.D., Zipp, B.J., Ludwig-Muller, J., Masuno, M.N., Molinski, T.F., Abel, S.: Arabidopsis glucosyltransferase UGT74B1 functions in glucosinolate biosynthesis and auxin homeostasis. - Plant J. 40: 893-908, 2004.

Halkier, B.A.: General introduction to glucosinolates. - In: Kopriva, S. (ed.): Advances in Botanical Research. Vol. 80. Pp.1-14. Elsevier, London 2016.

Halkier, B.A., Du, L.: The biosynthesis of glucosinolates. Trends Plant Sci. 2: 425-431, 1997.

Halkier, B.A., Gershenzon, J.: Biology and biochemistry of glucosinolates. - Annu. Rev. Plant Biol. 57: 303-333, 2006.

Hansen, B.G., Kliebenstein, D.J., Halkier, B.A.: Identification of a flavin-monooxygenase as the S-oxygenating enzyme in aliphatic glucosinolate biosynthesis in Arabidopsis. - Plant J. 50: 902-910, 2007.

Hansen, C.H., Du, L., Naur, P., Olsen, C.E., Axelsen, K.B., Hick, A.J., Pickett, J.A., Halkier, B.A.: CYP83B1 is the oxime-metabolizing enzyme in the glucosinolate pathway in Arabidopsis. - J. biol. Chem. 276: 24790-24796, 2001.

Hemm, M.R., Ruegger, M.O., Chapple, C.: The Arabidopsis ref2 mutant is defective in the gene encoding CYP83A1 and shows both phenylpropanoid and glucosinolate phenotypes. Plant Cell 15: 179-194, 2003.

Hoecker, U., Toledo-Ortiz, G., Bender, J., Quail, P.H.: The photomorphogenesis-related mutant redl is defective in CYP83B1, a red light-induced gene encoding a cytochrome P450 required for normal auxin homeostasis. - Planta 219: 195-200, 2004.

Hull, A.K., Vij, R., Celenza, J.L.: Arabidopsis cytochrome P450s that catalyze the first step of tryptophan-dependent indole-3-acetic acid biosynthesis. - Proc. nat. Acad. Sci. USA 97: 2379-2384, 2000.

Jefferson, R.A., Kavanagh, T.A., Bevan, M.W.: GUS fusions: beta-glucuronidase as a sensitive and versatile gene fusion marker in higher plants. - EMBO J. 6: 3901-3907, 1987.

Johnson, M., Zaretskaya, I., Raytselis, Y., Merezhuk, Y., McGinnis, S., Madden, T.L.: NCBIBLAST: a better web interface. - Nucl. Acids Res. 36: W5-W9, 2008.

Latte, K.P., Appel, K.-E., Lampen, A.: Health benefits and possible risks of broccoli - an overview. - Food Chem. Toxicol. 49: 3287-3309, 2011.

Madsen, S.R., Olsen, C.E., Nour-Eldin, H.H., Halkier, B.A.: Elucidating the role of transport processes in leaf glucosinolate distribution. - Plant Physiol. 166: 1450-1462, 2014.

Maharjan, P.M., Dilkes, B.P., Fujioka, S., Pencik, A., Ljung, K., Burow, M., Halkier, B.A., Choe, S.: Arabidopsis gulliver 1/superroot2-7 identifies a metabolic basis for auxin and brassinosteroid synergy. - Plant J. 80: 797-808, 2014.

Mewis, I., Appel, H.M., Hom, A., Raina, R., Schultz, J.C.: Major signaling pathways modulate Arabidopsis glucosinolate accumulation and response to both phloem-feeding and chewing insects. - Plant Physiol. 138: 1149-1162, 2005.

Mewis, I., Khan, M.A.M., Glawischnig, E., Schreiner, M., Ulrichs, C.: Water stress and aphid feeding differentially influence metabolite composition in Arabidopsis thaliana (L.). - PLoS ONE 7: e48661, 2012.

Mewis, I., Tokuhisa, J.G., Schultz, J.C., Appel, H.M., Ulrichs, C., Gershenzon, J.: Gene expression and glucosinolate accumulation in Arabidopsis thaliana in response to generalist and specialist herbivores of different feeding guilds and the role of defense signaling pathways. Phytochemistry 67: 2450-2462, 2006.

Mikkelsen, M.D., Hansen, C.H., Wittstock, U., Halkier, B.A.: Cytochrome P450 CYP79B2 from Arabidopsis catalyzes the conversion of tryptophan to indole-3-acetaldoxime, a precursor of indole glucosinolates and indole-3-acetic acid. J. biol. Chem. 275: 33712-33717, 2000.

Mikkelsen, M.D., Naur, P., Halkier, B.A.: Arabidopsis mutants in the $C-S$ lyase of glucosinolate biosynthesis establish a critical role for indole-3-acetaldoxime in auxin homeostasis. - Plant J. 37: 770-777, 2004.

Mikkelsen, M.D., Petersen, B.L., Glawischnig, E., Jensen, A.B., Andreasson, E., Halkier, B.A.: Modulation of CYP79 genes and glucosinolate profiles in Arabidopsis by defense signaling pathways. - Plant Physiol. 131: 298-308, 2003.

Mizutani, M., Ward, E., Ohta, D.: Cytochrome P450 superfamily in Arabidopsis thaliana: isolation of cDNAs, differential expression, and RFLP mapping of multiple cytochromes P450. - Plant mol. Biol 37: 39-52, 1998.

Moldrup, M.E., Salomonsen, B., Geu-Flores, F., Olsen, C.E., Halkier, B.A.: De novo genetic engineering of the camalexin biosynthetic pathway. - J. Biotechnol. 167: 296-301, 2013.

Morant, M., Ekstrom, C., Ulvskov, P., Kristensen, C., Rudemo, M., Olsen, C.E., Hansen, J., Jorgensen, K., Jorgensen, B., Moller, B.L., Bak, S.: Metabolomic, transcriptional, hormonal, and signaling cross-talk in superroot2. - Mol. Plant 3: 192-211, 2010.

Nafisi, M., Goregaoker, S., Botanga, C.J., Glawischnig, E., Olsen, C.E., Halkier, B.A., Glazebrook, J.: Arabidopsis cytochrome P450 monooxygenase $71 \mathrm{~A} 13$ catalyzes the conversion of indole-3-acetaldoxime in camalexin synthesis. - Plant Cell 19: 2039-2052, 2007.

Nafisi, M., Sønderby, I.E., Hansen, B.G., Geu-Flores, F., Nour-Eldin, H.H., Nørholm, M.H.H., Jensen, N.B., Li, J., Halkier, B.A.: Cytochromes P450 in the biosynthesis of glucosinolates and indole alkaloids. - Phytochem. Rev. 5: 331-346, 2006.

Naur, P., Petersen, B.L., Mikkelsen, M.D., Bak, S., Rasmussen, H., Olsen, C.E., Halkier, B.A.: CYP83A1 and CYP83B1, two nonredundant cytochrome P450 enzymes metabolizing oximes in the biosynthesis of glucosinolates in Arabidopsis. Plant Physiol. 133: 63-72, 2003.

Nour-Eldin, H.H., Hansen, B.G., Norholm, M.H.H., Jensen, J.K., Halkier, B.A.: Advancing uracil-excision based cloning towards an ideal technique for cloning PCR fragments. Nucl. Acids Res. 34: e122, 2006.

Pang, Q.Y., Chen, S.X., Li, L.X., Yan, X.F.: Characterization of glucosinolate-myrosinase system in developing salt cress Thellungiella halophila. - Physiol. Plant. 136: 1-9, 2009.

Pfalz, M., Vogel, H., Kroymann, J.: The gene controlling the 
Indole Glucosinolate Modifierl quantitative trait locus alters indole glucosinolate structures and aphid resistance in Arabidopsis. - Plant Cell 21: 985-999, 2009.

Piotrowski, M., Schemenewitz, A., Lopukhina, A., Muller, A., Janowitz, T., Weiler, E.W., Oecking, C.: Desulfoglucosinolate sulfotransferases from Arabidopsis thaliana catalyze the final step in the biosynthesis of the glucosinolate core structure. - J. biol. Chem. 279: 50717-50725, 2004.

Reymond, P., Weber, H., Damond, M., Farmer, E.E.: Differential gene expression in response to mechanical wounding and insect feeding in Arabidopsis. - Plant Cell 12: 707-720, 2000.

Riach, A.C., Perera, M.V.L., Florance, H.V., Penfield, S.D., Hill, J.K.: Analysis of plant leaf metabolites reveals no common response to insect herbivory by Pieris rapae in three related host-plant species. - J. exp. Bot. 66: 2547-2556, 2015.

Rombauts, S., Dehais, P., Van Montagu, M., Rouze, P.: PlantCARE, a plant cis-acting regulatory element database. Nucl. Acids Res. 27: 295-296, 1999.

Rose, P., Faulkner, K., Williamson, G., Mithen, R.: 7-Methyl-sulfinylheptyl and 8-methylsulfinyloctyl isothiocyanates from watercress are potent inducers of phase II enzymes. - Carcinogenesis 21: 1983-1988, 2000.

Schultz, J., Milpetz, F., Bork, P., Ponting, C.P.: SMART, a simple modular architecture research tool: identification of signaling domains. - Proc. nat. Acad. Sci. USA 95: 5857-5864, 1998.

Smolen, G., Bender, J.: Arabidopsis cytochrome P450 cyp83B1 mutations activate the tryptophan biosynthetic pathway. Genetics 160: 323-332, 2002.

Stotz, H.U., Sawada, Y., Shimada, Y., Hirai, M.Y., Sasaki, E., Krischke, M., Brown, P.D., Saito, K., Kamiya, Y.: Role of camalexin, indole glucosinolates, and side chain modification of glucosinolate-derived isothiocyanates in defense of Arabidopsis against Sclerotinia sclerotiorum. Plant J. 67: 81-93, 2011.

Textor, S., Gershenzon, J.: Herbivore induction of the glucosinolate-myrosinase defense system: major trends, biochemical bases and ecological significance. - Phytochem. Rev. 8: 149-170, 2009.

Warwick, S.I., Francis, A., Al-Shehbaz, I.A.: Brassicaceae: species checklist and database on CD-Rom. - Plant Syst. Evol. 259: 249-258, 2006.

Weiler, E.W., Jourdan, P.S., Conrad, W.: Levels of indole-3-acetic acid in intact and decapitated coleoptiles as determined by a specific and highly sensitive solid-phase enzyme immunoassay. - Planta 153: 561-571, 1981.

Yang, Y.M., Xu, C.N., Wang, B.M., Jia, J.Z.: Effects of plant growth regulators on secondary wall thickening of cotton fibres. - Plant Growth Regul. 35: 233-237, 2001.

Zang, Y.X., Lim, M.H., Park, B.S., Hong, S.B., Kim, D.H.: Metabolic engineering of indole glucosinolates in Chinese cabbage plants by expression of Arabidopsis CYP79B2, CYP79B3, and CYP83B1. - Mol. Cells 25: 231-241, 2008.

Zhang, Z.L., Ji, R.H., Li, H.Y., Zhao, T., Liu, J., Lin, C.T., Liu, B.: CONSTANS-LIKE 7 (COL7) is involved in phytochrome B (phyB)-mediated light-quality regulation of auxin homeostasis. - Mol. Plant 7: 1429-1440, 2014.

Zhang, Z.Y., Ober, J.A., Kliebenstein, D.J.: The gene controlling the quantitative trait locus EPITHIOSPECIFIER MODIFIER1 alters glucosinolate hydrolysis and insect resistance in Arabidopsis. - Plant Cell 18: 1524-1536, 2006. 